\title{
AUTONOMIC BLOCK, CARDIOVASCULAR DEPRESSION AND HISTAMINE RELEASE PRODUCED BY POLYMYXIN B IN THE CAT
}

\author{
Chingmuh Lee, Sandy Ricker, and Ronald L. Katz
}

WHEN INJECTED INTRAVENOUSLY, polymyXin B in neuromuscular blocking doses causes profound hypotension and bradycardia in the cat. ${ }^{1.2}$ The mechanisms of action of these side effects are unclear. Histamine release and ganglion block may be contributory. ${ }^{3,4}$ Brezenoff and Gertner have injected small doses of polymyxin $B$ $(0.1-0.5 \mathrm{mg})$ close-arterially into the ganglion of the cat and demonstrated that polymyxin $B$ releases histamine in the ganglion and also blocks the ganglionic transmission. ${ }^{4}$ The present study quantifies the autonomic, the cardiovascular, and the histamine-releasing effects of polymyxin $B$ in the cat.

\section{METHODS}

Nine cats averaging $3.5 \mathrm{~kg}$ (S.D., 0.2) in weight were anaesthetized with alphachloralose 70 $\mathrm{mg} \cdot \mathrm{kg}^{-1}$ and pentobarbitone $5 \mathrm{mg} \cdot \mathrm{kg}^{-1}$ injected intraperitoneally. Tracheostomy was performed. Ventilation was controlled with a Palmar Pump delivering air at a rate of 24 limes per minute ( $\mathrm{Pa}_{\mathrm{CO}_{2}} 3.99-4.92 \mathrm{kPa}$ [30-37 torr]). Arterial blood pressure was monitored through a cannula placed by cut-down in the left common carotid or a femoral artery. A subcutaneous vein was cannulated for injection of drugs. The right vagus nerve and the right sympathetic trunk were exposed in the neck, separated, severed and each was stimulated distally. In addition, the sympathetic trunk was dissected further cephalad to its entrance to the base of the skull, for post-ganglionic stimulation. To protect the nerve structures from drying, skin flaps in the neck were turned to form a pool which was filled with mineral oil saturated with 0.89 per cent saline solution warmed to body temperature. The preganglionic and postganglionic sympathetic trunks were stimulated one at a time. The stimulation, repeated once every 100 seconds, consisted of 200 square pulses

Chingmuh Lee, M.D., Sandy Ricker, B.S., C.M.T Ronald L. Katz, M.D. Department of Anesthesiology, UCLA School of Medicine, Los Angeles, California, 90024.

Abstract presented at the Fifth European Congress of Anaesthesiology, Paris, France, September 5, 1978.

Canad. Anaesth. Soc. J., vol. 26, no. 3, May 1979 of $0.5 \mathrm{msec}$ duration delivered in 10 seconds (20 $\mathrm{Hz}$ ) through shielded electrode pairs. The stimulus was supramaximal (5-20 volts), gener-

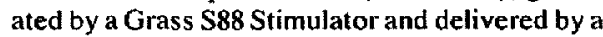
Grass SIU5 Stimulus Isolation Unit. The skull was immobilized with a slight extension of the neck. Contraction of the ipsilateral nicitating membrane was measured with a sterotactically positioned Grass FT 0.03 transducer, amplified, and recorded on a Gould recorder. A baseline tension of approximately $5 \mathrm{gm}$ was maintained. The vagus nerve was stimulated in a similar fashion. The number of $P$ (sino-atrial) waves of the electrocardiogram recorded during the stimulation period was compared with the number of $P$ waves recorded during the preceding 10 seconds. Failure of the stimulation to reduce the sino-atrial rate was attributed to vagal block.

After obtaining control values for the heart rate, the mean arterial blood pressure, the nictitating membrane response to pre-ganglionic and post-ganglionic stimulation and the bradycardiac response to stimulation of the vagus, as well as the control blood sample for histamine, polymyxin $B$ was injected in the following incremental doses: $1 \mathrm{mg} \cdot \mathrm{kg}^{-1}, 4 \mathrm{mg} \cdot \mathrm{kg}^{-1}, 5 \mathrm{mg} \cdot \mathrm{kg}^{-1}$, and $10 \mathrm{mg} \cdot \mathrm{kg}^{-1}$ of the base. Polymyxin B was prepared from powder by adding 0.89 per cent saline. Each successive dose was injected 5 to 8 minutes after the preceding dose. The time interval was required for the effects of each incremental dose to develop fully. The cumulative doses were thus $1 \mathrm{mg} \cdot \mathrm{kg}^{-1}, 5 \mathrm{mg} \cdot \mathrm{kg}^{-1}, 10 \mathrm{mg} \cdot \mathrm{kg}^{-1}$, and 20 $\mathrm{mg} \cdot \mathbf{k g}^{-1}$. The variables previously described were re-examined before the injection of each successive incremental dose. Effects of each dose of polymyxin $B$ were analyzed by statistical comparisons of groups of test values with the corresponding group of control values from each variable, each cat serving as its own control, by use of Student's t-tests for paired values. To minimize the possibility of inducing hypotension by excessive blood sampling, the size of the blood samples was limited to $3 \mathrm{ml}$ each time, $15 \mathrm{ml}$ total in each cat. Each time a blood sample was taken $5 \mathrm{ml}$ of lactated Ringer's solution with 5 per cent 96 
also received $30 \mathrm{ml} / \mathrm{kg}$ of lactated Ringer's solution with 5 per cent dextrose within the preceding two to three hours. Blood samples were frozen until a later date for the determination of the whole blood histamine concentration flurometrically. ${ }^{5}$ During the experiment, the oesophageal temperature directly under the pool of mineral oil ranged from $35.5^{\circ}$ to $37.2^{\circ} \mathrm{C}$. Whole body warming was achieved by a warming mattress under and a heating lamp over the cat. After completion of the injection of polymyxin B observation was continued for 90 minutes to quantify spontaneous recovery. In two cats, the neurally evoked compound electromyographic response of the tibialis anterior muscle was also recorded, to verify that cats used in this study had neuromuscular sensitivity similar to cats used in previous studies.

\section{RESULTS}

The results are illustrated in Figure 1 and summed up in Figure 2. At control, the mean arterial blood pressure averaged $14.63 \mathrm{kPa}$ (S.E.M., 0.93) (110 torr, S.E.M., 7) and the heart rate 152 (S.E.M., 10) beats per minute. Polymy$x$ in $B$ reduced both values. The effects were dose-dependent. (Figure 2.) Estimated from Figure 2 , polymyxin $B$ base $8.5 \mathrm{mg} \cdot \mathrm{kg}^{-1}$ would cause an average 50 per cent drop in the mean arterial pressure. The onset of hypotension and bradycardia was observed in approximately 10 to 20 seconds. The peak effect occurred in one to six minutes. Contraction of the nictitating membrane elicited by pre-ganglionic and post-ganglionic stimulation of the sympathetic trunk both diminished (Figure 1). Estimated graphically the average 50 per cent blocking dose would be 7 $\mathrm{mg} \cdot \mathrm{kg}^{-1}$, and $8 \mathrm{mg} \cdot \mathrm{kg}^{-1}$, respectively. The peak effect of each incremental dose of polymyxin $B$ was observed in five to eight minutes.

Stimulation of the vagus at control produced complete sinus arrest throughout the 10-second stimulation period in five out of nine cats. The remaining four cats displayed a few sinus beats following an initial complete arrest. Over-all the heart rate during the 10 -second stimulation period averaged 10 (S.E.M., 6) per cent of the normal rate. This 90 per cent reduction of the heart rate was the control vagal response. Polymyxin B demonstrated dose-dependent vagal block (Figure 1). An estimated 10.5 $\mathrm{mg} \cdot \mathrm{kg}^{-1}$ of Polymyxin B base would halve the vagal response (Figure 2).

The whole blood histamine concentration was 4.6 (S.E.M., 0.6) $\mu \mathrm{g} / \mathrm{dl}$ at control. After 10

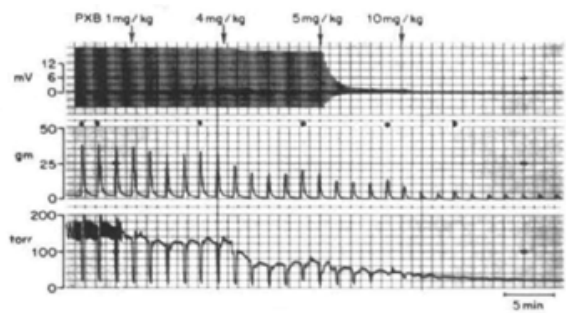

Figure I Neuromuscular, autonomic, and cardiovascular effects of polymyxin $B(P X B)$ in the cat. Upper tracing: neurally evoked compound electromyographic response of the tibialis anterior muscle. Middle tracing: contraction of the nictitating membrane elicited by pre-ganglionic (non-dotted) or postganglionic (dotted) stimulation of the cervical sympathetic trunk. Lower tracing: arterial blood pressure (switched to mean pressure prior to administration of PXB $1 \mathrm{mg} \cdot \mathrm{kg}^{-1}$ ). Transient recurrent episodic hypotension to nearly zero torr was the result of stimulation of the vagus. The accompanying electrocardiogram, recorded separately for quantification of vagal block. was not presented.

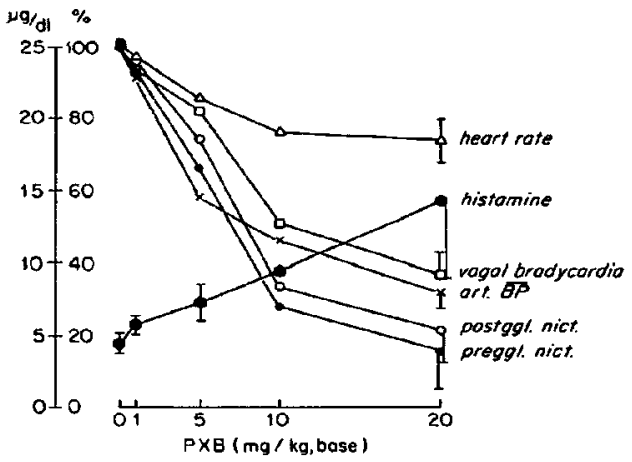

Figure 2 Effects of polymyxin $B$ (PXB) on the heart rate, the bradycardiac response to stimulation of the vagus, the mean arterial blood pressure, the contraction of the nictitating membrane elicited by postganglionic and pre-ganglionic stimulation of the cervical sympathetic trunk (above in order of increasing sensitivity to $\mathrm{PXB}$ ), and the whole blood histamine concentration in the anaesthetized cat. The left scale on the longitudinal axis, in $\mu \mathrm{g} / \mathrm{dl}$, is for histamine values only. The right scale, in percentage, is for all other variables. Bars indicate standard errors of mean values, and have been omitted where appropriate to improve graphic clarity.

$\mathrm{mg} \cdot \mathrm{kg}^{-1}$ of polymyxin $\mathrm{B}$, it increased to 9.1 (S.E.M., 2.3) $\mu \mathrm{g} / \mathrm{dl}$ and after $20 \mathrm{mg} \cdot \mathrm{kg}^{-1}$ to 15.5 (S.E.M., 6.2) $\mu \mathrm{g} / \mathrm{dl}$. (Figure 2.) Statistical analysis of histamine data, however, revealed low levels of significance, $\mathrm{p}<0.1$ for $10 \mathrm{mg} \cdot \mathrm{kg}^{-1}$ and $20 \mathrm{mg} \cdot \mathrm{kg}^{-1}$ doses, insignificant at lower 
doses. With this exception, effects of polymyxin $B$ on other variables were consistent, progressive, and statistically significant $(p<0.01)$.

All cats survived 90 minutes after the completion of injection of polymyxin $B$, but the recovery was poor. The mean arterial blood pressure recovered approximately 25 to 35 per cent of loss, i.e. , from 30 per cent of control to $50-60$ per cent of control. The heart rate recovered approximately 50 per cent of loss, i.e., from $75-80$ per cent of control to approximately 90 per cent of control. The nictitating membrane contraction recovered $0-50$ per cent of control, the vagal response $10-40$ per cent.

\section{Discussion}

The observed cardiovascular effects of polymyxin B were characterized by hypotension and bradycardia. Obviously compensatory tachycardiac sympathetic reflexes for hypotension were blocked. As polymyxin B does not cross the blood-brain barrier, ${ }^{6}$ these effects cannot be attributed to central nervous system depression. The peripheral autonomic block was both preganglionic and post-ganglionic, because the nictitating membrane response diminished whether the site of sympathetic stimulation was proximal or distal to the ganglion. Because the response to pre-ganglionic stimulation tended to be only slightly more depressed (Figure 1), blockage distal to the ganglion might play a more important role. It is not clear whether the blockage of the ganglionic and the post-ganglionic neuro-effector transmissions was prejunctional or postjunctional. Regarding the neuromuscular effects of polymyxin B Wright and Collier ${ }^{7}$ have observed a decrease in the muscle response to exogenously administered acetylcholine, but failed to detect an impaired acetylcholine output during nerve stimulation. This indicated postjunctional block. Besides blocking the neuromuscular transmission, polymyxin B also depressed the muscle response to direct stimulation and had a local anaesthetic effect on the nerve."

In addition to ganglionic and sympathetic block, histamine release may also cause cardiovascular depression in the cat. ${ }^{6.8}$ In vitro, polymyxin B is a potent "selective" histamine releaser, being $\mathbf{5 5 0}$ times as potent as tubocurarine on an equimolar basis in releasing histamine from mast cells obtained from the peritoneal fluid of rats. ${ }^{3}$ Clinically, pain at the injection site and occasional anaphylactoid response also suggest histamine release. ${ }^{6}$ In this aspect, our results are not conclusive. Large individual variability with low levels of statistical significance may be caused in part by the intrinsic variability in the assay technique. It may also suggest that histamine release is not the main cause of hypotension in the cat. The suggestion is supported by an obvious lack of correlation between the hypotension and the histamine concentration among the cats and agrees with Brezenoff and Gertner ${ }^{4}$ who have concluded that the ganglion blocking action of polymyxin $B$ is not mediated by histamine release inside the ganglion. Our inability to demonstrate the episodes of transient hypotension occurring with a well-defined latency ${ }^{9}$ characteristic of "selective" histamine relcase further suggests that the histamine release, if any, might not be "selective". ${ }^{3}$ but possibly destructive and prolonged.

Not only the neuromuscular transmission but also the autonomic and the cardiovascular functions of the cat recovered poorly after large doses of polymyxin B. Survey of the literature reveals that polymyxin B causes both functional and morphological damage to a wide variety of tissues in addition to the susceptible bacteria. ${ }^{1,2,4,6,8,10-12}$ Chemically polymyxin $\mathbf{B}$ is a polycationic surface-active agent ${ }^{6}$ (detergent). Biologically it disorganizes the outer bilayer of the cell membrane, by interacting with phosphatidylethanolamine, to cause an increase in permeability and a breakdown of the cellular barrier. ${ }^{6.10,12-14}$ of all the antimembrane compounds, the polymyxins are the only ones with a sufficient margin of safety to permit clinical use. Most demonstrated or suspected sites of polymyxin B toxicity, such as the neuromuscular junction, the muscle, the motor nerve terminal, the autonomic synapses, the sensory nerve ending, the desheathed nerve, ${ }^{7}$ the lens, $"$ the mast cell $^{3}$ and the kidney ${ }^{6.10}$ have little in common but free accessibility and possible susceptibility of the cell membrane to the antimembrane activity of the compound. Lack of tissue specificity of action makes it implausible and unnecessary to explain the neuromuscular and the autonomic effects of polymyxin $B^{7}$ from the cholinergic point of view. Therefore, we propose a common antimembrane mechanism of action to explain all biological effects of polymyxin $B$, including its antibacterial action, and to explain its narrow margin of safety and its narrow range of scatter of dose requirement among side effects.

A generalized membrane-active non-cholinergic mechanism of action for the multiple toxic effects is also in agreement with the recog- 
nized features of neuromuscular block induced by polymyxin $B$. An increased permeability of the cell membrane at the motor nerve terminal may explain the reported lack of decrease in acetylcholine output. ${ }^{7}$ Anticholinesterases, being "facilitatory" drugs which enhance and maintain a post-stimulus depolarizing afterpotential, ${ }^{16}$ may enhance instead of reversing the block,' because conceivably polymyxin B may also prevent normal repolarization by increasing the permeability. Long duration of neuromuscular blocking action agrees with the long duration of antibacterial action. Prolonged exposure to polymyxin B may produce a cumulative effect and result in deterioration of the neuromuscular preparation, but may not change the nature of block. ${ }^{1,2}$ Conceivably, any agent which reverses the neuromuscular effect may also reverse other side effects of polymyxin B with the same mechanism of action and, thus, with a similar dose requirement. As a matter of fact, a neuromuscular reversing dose of 4-aminopyridine has been observed also to reduce the hypotensive effect of polymyxin B. ${ }^{2.17}$

\section{SUMMARY}

The present study quantifies the autonomic block, the cardiovascular depression and the histamine releasing effects of polymyxin $B$ in nine anaesthetized cats. The dose requirements for 50 per cent depression of the mean arterial blood pressure, the bradycardiac response to vagal stimulation, and the contraction of the nictitating membrane elicited by pre-ganglionic and postganglionic stimulation of the cervical sympathetic trunk have a narrow range of scatter, being of the order of $6-12 \mathrm{mg} \cdot \mathrm{kg}^{-1}$ of the polymyxin $B$ base. The neuromuscular blocking dose $\left(E_{30}\right)$, previously determined and hereby confired, also falls in the same range. Bradycardia and possibly histamine release are also observable. The relatively unremarkable effect of polymyxin $B$ on the heart rate can be attributed to the balance between the vagal, sympathetic and ganglionic blocks, as well as the possible histamine release. All effects are long-lasting. Thus lack of tissue specificity makes it implausible to explain the neuromuscular and the cardiovascular effects of polymyxin $B$ solely by the cholinergic mechanism of action. Ganglionic block and histamine release do not completely explain hypotension induced by polymyxin $B$. We propose that all biological effects of polymyxin $B$ derive from a common mechanism of action, which may be its antimembrane antibacterial action. We would like to alert anaesthetists to the possibility that polymyxin B may cause severe multiple organ system depression, in addition to neuromuscular block.

\section{Résumé}

Le blocage du système nerveux autonome, la dépression du système cardiovasculaire el l'effet histamino-libérateur de doses de polymyxin B allant jusqu'à $20 \mathrm{mg} \cdot \mathrm{kg}^{-1}$ ont été mesurés sur neuf chats anesthésiés et ventilés. La dose efficace 50 pour cent $\left(E D_{s 0}\right)$ pour produire une baisse de la tension artérielle, la bradycardie par stimulation vagale, la contraction de la membrane nictitante par stimulation pré- el postganglionnaire du tronc sympathique cervical, ainsi que le blocage de la transmission neuromusculaire se situe dans l'éventail de dispersion étroit de 6 à $12 \mathrm{mg} \cdot \mathrm{kg}^{-1}$ de la base de polymyxin $\mathrm{B}$. De la bradycardie et une libération d'histamine ont aussi été observés. Tous ces effets sont de longue durée. Les résultats obtenus montrent l'absence de spécificité tissulaire et suggèrent la possibilité que tous ces effets biologiques de la polymyxin B puissent s'expliquer par un mécanisme commun d'action, soit l'activité de l'antibiotique sur la permabilité de la membrane. En plus de produire un blocage ganglionnaire, la polymyxin B pourrait agir en aval du ganglion pour causer la dépression cardio-vasculaire.

\section{REFERENCES}

1. Lee, C., Chen, D. \& Nagel, E.L. Neuromuscular block by antibiotics: polymyxin B. Anesth. Analg. 56: 373 (1977).

2. DE Silva, A.J.C. \& LeE, C. Neuromuscular and cardiovascular depression produced by prolonged exposure to polymyxin B. Canad. Anaesth. Soc. J. 25: 303 (1978).

3. Ellis, H.V. III, Johnson, A.R., \& Moran, N.C. Selective release of histamine from rat mast cells by several drugs. J. Pharmacol. Exp. Ther. 175: 627 (1970).

4. Brezenoff, H.E. \& Gertner, S.B. The actions of polymyxin B and histamine on ganglionic transmission. Canad. J. Physiol. Pharmacol. 50: 824 (1972).

5. Shore, P.A., Burkhalter, A., \& Cohn, V.H., JR. A method for the fluorometric assay of histamine in tissues. J. Pharmacol. Exp. Ther, 127: 182 (1959).

6. Goodman, L.S. \& GILman, A. The Pharmacological Basis of Therapeutics, Sth ed. New York: Macmillan Pub. Co. (1975). Chapter 29 on histarnine by Douglas, W.W. (p. 593), and Chapter 61 on antibioties by Weinstein. L. (pp. 1230-1232).

7. WRIGHT, J.M. \& COLLIER, B. The site of the 
neuromuscular block produced by polymyxin $B$ and rolitetracycline. Canad. J. Physiol. Pharmacol. 54: $926(1976)$

8. Flacke, W., Atanackovic, D., Gillis, R.A., \& ALPER, M.H. The actions of histamine on the mammalian heart. J. Pharmacol. Exp. Ther. 155: 271 (1967).

9. Paton, W.D.M. Histamine release by compounds of simple structure. Pharmacol. Review 9: 269 (1957).

10. Braude, A.I. Antimicrobial Drug Therapy, Vol. VIII in the series Major Problems in Internal Medicine (Smith, L.H., Jr., ed.). Philadelphia, London, Toronto: W.B. Saunders: pp. 6, 22(1976).

11. Cotlier, E. \& APPLE, D. Cataracts induced by the polypeptide antibiotic polymyxin B sulfate. Exp. Eye Res. 16: 67 (1973).

12. KOIKE, M., IIDA, K., \& MatsUo, T. Electron microscopic studies on mode of action of polymyxin. J. Bacteriol. 97 : 448 (1969).
13. Hsu Chen, C.C. \& Feingold, D.S. The mechanism of polymyxin B action and selectivity toward biological membranes. Biochemistry 12: 2105 (1973).

14. Feingold. D.S., Hsu Chen, C.C., \& Sud, 1.J. Basis for the selectivity of action of the polymyxin antibiotics on cell membranes. Ann. N.Y. Acad. Sci. 235: 480 (1974).

15. RIKER, W.F., JR. Pre-junctional effects of neuromuscular blocking and facilitatory drugs. Chapter in Muscle Relaxants edited by Katz, R.L. New York: American Elsevia Pub. Co.; pp. 59-102 (1975).

16. Van Nyhuis, L.S., Miller, R.D., \& Fogdall, R.P. The interaction between d-tubocurarine, pancuronium, polymyxin $B$ and neomycin on neuromuscular function. Anesth. Analg. 55: 224 (1976). 